\title{
Una aproximación multimodal de la representación mediática de las protestas del Sector Educación
}

Recibido: 17 de febrero 2016

Revisado: 9 de mayo 2016

Aprobado: 2 de junio 2016

Daniel Fernández Fernández

Costarricense. Licenciado en Psicología por la Universidad de Costa Rica y egresado de la Maestría Académica en Lingüística de la misma universidad. Docente de la Escuela de Psicología de la Universidad de Costa Rica e investigador del Instituto de Investigación en Educación de la UCR. A su vez; funge como docente e investigador en el Instituto de Estudios de la Mujer en la Universidad Nacional de

Costa Rica.

Correo electrónico: danielfernand@gmail.com

Lua Studt Solano

Costarricense. Bachiller en Enseñanza del Inglés y egresada de la Maestría Académica en Lingüística por la Universidad de Costa Rica. Trabaja como Intérprete en Language Line Solutions y es docente en la Universidad de Costa Rica Correo electrónico: luastudt05@gmail.com
Resumen: En el presente artículo se analiza la representación de las protestas sociales concernientes a las reivindicaciones del sector educación en una muestra de noticias difundidas en el telediario Noticias REPRETEL de Costa Rica durante el mes de mayo del año 2014. La investigación se desarrolla a partir de un abordaje metodológico del discurso multimodal; con el acometido de discernir los diferentes mecanismos persuasivos con los cuales las protestas del sector educación son enmarcadas.

Palabras clave: representación; protestas; educadores; discurso multimodal; persuasión.

\section{A Multimodal Approach of the Media Representation of Protest in the Educational Sector}

Abstract: The current article analyses the representation of social protest; concerning the demands made by the educational sector in a sample of news reports that were broadcast on the Costa Rican newscast REPRETEL throughout May; 2014. This research is carried out using a methodological multimodal analysis standpoint and the main aim is to ascertain the different persuasive mechanisms used to portray protest in the educational sector.

Keywords: representation; protest; teachers; multimodal discourse; persuasion. 
"La televisión, que pretende ser un instrumento que refleja la realidad, acaba convirtiéndose en un instrumento que crea una realidad" (Bourdieu 2001, 28).

\section{Introducción}

El análisis que se propone a continuación parte del principio según el cual el discurso que presentan los medios de comunicación sobre las protestas sociales está inexorablemente ligado a un contexto económico y social determinado. Por esta razón, los medios no tienen una postura neutral frente a la realidad que comunican, sino que están atravesados por postulados ideológicos que determinan el decurso de su acción comunicativa.

Las protestas que dan pie al presente artículo se producen en un terreno de confrontación política. Las noticias analizadas versan en torno al conflicto más importante en los últimos 30 años entre el Gobierno Central y los gremios del sector educación. El antecedente más importante en esta línea fue la huelga del Magisterio Nacional del año 1995, la cual constituyó la cúspide de un proceso de malestar por parte de los educadores en relación con las reformas al sistema de pensiones que se comenzaron a gestar desde los años 80 por medios de los Programas de Ajuste Estructural (Mora, 2009).

La huelga correspondiente al año 2014 ocurre en el proceso de transición de la Administración de la presidenta Laura Chinchilla Miranda (2010-2014) y la Administración del presidente Luis Guillermo Solís Rivera (2014-2018). La razón del conflicto responde a la implementación de un nuevo sistema del pago por parte del Ministerio de Educación Pública, cuya planilla es de alrededor de setenta y cinco mil personas (Mena, 2014). La puesta en funcionamiento de dicho sistema generó múltiples fallas que provocaron que muchos educadores no recibiesen sus respectivos salarios durante un periodo considerable. Así se originó un malestar generalizado que desembocó en una huelga de veinte días de duración.

El análisis busca determinar la forma en que son representadas las protestas sociales y sus participantes a través del discurso noticioso de la cadena televisiva REPRETEL. Es importante tener en cuenta que "todo discurso se construye relacionalmente, y por tanto toda identidad también. Por consiguiente, (...) la conformación identitaria dependerá de la relación que establezca cada colectivo con los demás grupos de protesta, con los medios de comunicación, con el Estado, para nombrar los principales actores" (Romanutti, 2012, p. 266).

Los medios de comunicación coadyuvan en la configuración del imaginario social entorno a aquellas personas que se adhieren a la protesta en sí. En 
este sentido, la inquietud por representación que llevan a cabo los medios sobre los participantes del movimiento de educadores resulta de gran importancia, en la medida en que a través de la misma se dota a los espectadores con recursos semióticos particulares, los cuales facultan la plausibilidad de una $u$ otra identificación en torno a la protesta y a sus propulsores.

\section{Discurso multimodal}

La investigación que que genera el presente texto es tributaria de la visión general que conlleva la noción foucaultiana de discurso, que consiste en una realidad supraindividual, en un tipo de práctica que pertenece a colectivos más que a individuos y que está siempre situada en diversas áreas o campos sociales (Diaz-Bone et al. 2005).

Siendo que la configuración del objeto de investigación seleccionado conlleva diversos recursos semióticos, se emplea un abordaje desde la perspectiva del análisis del discurso multimodal (en adelante ADM). "El enfoque multimodal sostiene que las opciones no se dan solamente en el plano del lenguaje verbal sino simultáneamente junto con otros sistemas de opciones que se realizan junto con él" (Martín 2012, 64).

Sí, como señalan Calsamiglia y Tusón (2007), abordar el tema del discurso supone adentrarse en el entramado de las relaciones sociales, de las identidades y de los conflictos; o en otros términos, intentar entender cómo se expresan los diferentes grupos culturales en un momento histórico dado y con unas características socioculturales específicas. Por lo tanto, es imprescindible disponer de un instrumental teórico-metodológico que permita aprehender el conjunto amplio de manifestaciones que tienen lugar en dichos grupos.

La mayoría de esfuerzos de investigación orientados al análisis del discurso han procurado centrarse únicamente en el lenguaje oral o escrito, y como señala O'Halloran (2004), esto ha implicado ignorar o minimizar las contribuciones de otros recursos generadores de significado, lo que conlleva una mirada empobrecedora de las funciones y de los significados del discurso. En este marco, adscribimos la necesidad de una aproximación diferente al ámbito discursivo, que, sin dejar de lado las dimensiones tradicionalmente estudiadas, tenga en cuenta los múltiples recursos que entran en juego en los procesos de interacción social.

La lingüística sistémico-funcional (Halliday 1978) constituye el marco básico del que parte la perspectiva multimodal, al plantear que el lenguaje verbal se inscribe dentro de una semiótica social que apunta a dar cuenta de los sistemas de significación que se configuran en función de su inscripción contextual. La lingüística sistémico-funcional concibe el lenguaje como "un sistema semántico que se realiza formalmente y cuyo significado social es lo que faculta su comprensión, se prioriza el discurso o texto no solamente 
como evidencia del sistema, sino como elemento constitutivo de la cultura" (Martín 2012, 59).

De acuerdo con O'Halloran (2012), el enfoque sociosistémico de Halliday, del cual toma sus raíces el análisis multimodal, se fundamenta en los siguientes tres principios:

- La conceptualización del significado en tres estratos que relaciona características de bajo nivel que aparecen en los textos (por ejemplo: las imágenes y el sonido) con patrones semánticos de orden superior a través de conjuntos de sistemas léxico-gramaticales interrelacionados y, en última instancia, con contextos sociales de situación y con la cultura.

- La teoría de las metafunciones modela el potencial de significado de los recursos semióticos en tres 'metafunciones' diferentes:

- El significado ideativo (es decir nuestra concepción del mundo) involucra: el significado experiencial (la representación y la forma en que retratamos la experiencia en el mundo) y el significado lógico: la construcción de relaciones lógicas en ese mundo.

- El significado interpersonal: la puesta en acción de las relaciones sociales.

- El significado textual: la organización del significado en forma de textos y de unidades coherentes.

- La instanciación da cuenta de las relaciones entre las opciones concretas hechas en los textos y el potencial sistémico, con subpotenciales intermedios, registros que aparecen como patrones de opciones realizadas en tipos de textos (por ejemplo, en conversaciones casuales, debates y trabajos académicos) (p. 79).

El sentido que se privilegia en el presente artículo, supone que, a medida que los fenómenos multimodales -con las características previamente señaladas- se combinan, se da una producción de múltiples recursos semióticos y expansiones semánticas. Como señala Jewitt (2009), las relaciones intersemióticas, que surgen en función de la interacción de las distintas opciones semióticas, conllevan nuevas producciones semióticas. Justamente, esas nuevas producciones constituyen el área central de los estudios multimodales.

De este modo, siguiendo nuevamente a O'Halloran (2012), los problemas analíticos y teóricos del análisis multimodal del discurso se pueden concretizar según los siguientes puntos:

- Dar forma a los recursos semióticos que son fundamentalmente diferentes del lenguaje,

- Dar forma y analizar las expansiones intersemióticas de significado como opciones semióticas integradas en fenómenos multimodales, 
- Dar forma y analizar la resemiotización de los fenómenos multimodales en el despliegue de las prácticas sociales (p. 80).

Los distintos recursos semióticos y expansiones semánticas, que se generan a partir de la combinación de los fenómenos multimodales, generan 'relaciones 'inter-semióticas' (o inter-modales), que surgen a partir de la interacción de las opciones semióticas, conocidas como intersemiosis, constituyen un área central de los estudios multimodales" (Jewitt 2009).

En este sentido, se propone, como puente entre la noción de discurso señalada inicialmente y el planteamiento multimodal, tener presente la noción de semiosis social (Verón 1993), que conlleva la dimensión significante de los fenómenos sociales en tanto procesos de producción de sentido. En el caso particular que abordaremos en el presente artículo, esta producción de sentido debe ser tomada como una hipótesis de trabajo que dirige el análisis de los distintos recursos semióticos que aparecen en los textos comunicativos analizados. Así pues, planteamos desde ya la necesidad de integrar al análisis de los fenómenos discursivosestudios que trabajen en torno a la recepción de los mismos.

\section{Marcos de noticia y persuasión}

En el presente artículo, el abordaje de la compleja relación entre semiosis social e intersiomosis toma como centro analítico la noción de marco de noticia, es decir, que a partir de dicha noción se concretiza la relación entre los distintos recursos semióticos que presentan las noticias seleccionadas y los posibles efectos de expansión semiótica asociados a los mismos.

En relación con el campo de la imagen, el concepto de marco conlleva una forma de circunscripción de la realidad que configura la imagen. Aumont (2007) señala cuán difícil resulta separar el papel de la imagen de aquellos del dispositivo y del espectador al plantear que "si la imagen figurativa nos ofrece a la vista un campo visual, es que somos capaces de referir éste a un desglose del espacio por una mirada móvil, en los términos del encuadre prospectivo" (233).

En una línea homóloga al planteamiento fundamental de Aumont, en el presente artículo retomamos el planteamiento de Velásquez (2004), para quien el marco de la noticia se concibe como el esquema bajo el cual se escribe o se dice la noticia, esquema que tiene unas características sobresalientes que producen unos mensajes explícitos o implícitos para que el público interprete, evalúe $y$, eventualmente, piense en el tratamiento que se debe dar al asunto problemático sobre el que da cuenta la noticia, que en este caso se refiere a las protestas concernientes al sector educación.

Este planteamiento resulta fundamental, pues como señala Van Dijk (1990), las estructuras de las informaciones periodísticas condicionan, en muchos niveles, a los lectores para que desarrollen marcos interpretativos 
específicos. Estos últimos utilizan objetivos, normas, valores e ideologías que proporcionan interpretaciones singulares de los acontecimientos informativos y es en relación con este aspecto que cobra importancia el concepto de persuasión. En este sentido, el discurso noticioso conlleva efectos significantes que pueden hacer que los espectadores se decanten por una o por otra opción sobre distintos temas.

Van Dijk (1990), a su vez, afirma que "el discurso periodístico posee una gran cantidad de estrategias estándares para promover el proceso persuasivo de las afirmaciones" (126). Estas estrategias, que el autor identifica como elementos retóricos, pueden ser, por ejemplo: subrayar la naturaleza factual de los acontecimientos que presenta, construir una estructura sólida para la presentación de los hechos y promocionar información que posea dimensiones actitudinales y emocionales.

\section{Metodología}

Como se indicó anteriormente, el presente artículo se inscribe dentro de la tradición del análisis del discurso, el cual, de acuerdo con Martín (2012), es originalmente una subdisciplina lingüística que puede caracterizarse por la intersección de los contextos. Se desarrolla un tipo particular de análisis de discurso, que consiste en el análisis del discurso multimodal, que "constituye un paradigma emergente en el campo de los estudios del discurso que amplía el estudio del lenguaje per se al estudio del lenguaje en combinación con otros recursos tales como las imágenes, el simbolismo científico, la gestualidad, la acciones, la música, y el sonido" (O'Halloran 2012, 76).

Los medios de comunicación de donde se obtuvieron las noticias corresponden a los siguientes noticieros:

Tabla 1. Noticiero

Canal y adscripción empresarial

\begin{tabular}{lcc}
\hline Nombre del noticiero & Canal(es) & Empresa \\
\hline Noticias REPRETEL & Canal 6 & Grupo REPRETEL \\
Informe 11 Las Noticias & Canal 11 & S.A. \\
\hline Fuente: elaboración propia. & &
\end{tabular}

La elección de dichos noticieros responde a que históricamente se encuentran entre los que cuentan con más altos niveles del rating del país (Saborío y Zúñiga 2006); por lo tanto, su potencial de influencia resulta mayor. Se seleccionaron así cuatro noticias, las cuales se obtuvieron del Canal Youtube del grupo empresarial antes reseñado, en el cual se cuelgan algunas de las noticias que ordinariamente son presentadas en los canales televisivos propiamente dichos. Para la selección de las noticias, se tomaron en cuenta los siguientes criterios preliminares: 
- Calidad del recurso audiovisual disponible.

- Posibilidad de reconocer una causa o motivo de protesta claro.

- Claridad para identificar a los actores que representan dicho movimiento.

El análisis preliminar de los datos mostró una preminencia de la relación inter-semiótica discurso oral e imagen, razón por la cual en la transcripción del material de análisis se enfatizó en dicho aspecto. No obstante, se incluyeron otros recursos -aunque de manera no exhaustiva-, siempre y cuando estos no interfieran en la conjunción de los marcos de noticia mediante los cuales se representa las protestas del sector educación y sus participantes.

En la siguiente figura, se muestran los recursos que forman parte de la sistematización del material de análisis:

Figura 1: Recursos semióticos

Componentes y su relación

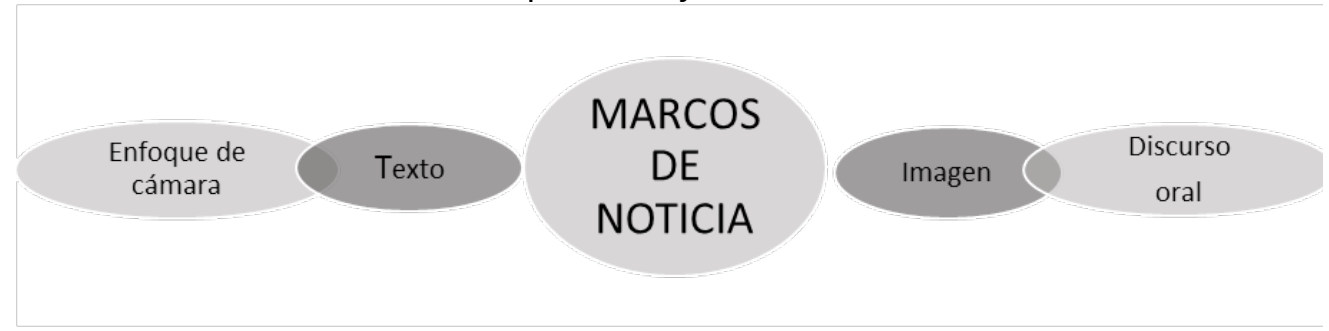

Fuente: elaboración propia.

Como se muestra en el anterior esquema, si bien es cierto que la relación intersemiótica entre el discurso oral y la imagen tiene un mayor énfasis para el análisis propuesto, se tuvo en cuenta la relación que tanto el texto escrito como los enfoques de cámara operan sobre dichos componentes, en relación directa con los marcos de noticia que circunscriben las informaciones sobre las manifestaciones y sus participantes. Se llevaron a cabo los siguientes procesos y estrategias de análisis:

- Descripción de recursos semióticos intervinientes.

- Identificación de la interrelación que se establece entre los recursos semióticos presentes y los marcos de noticia.

- Determinación de posibles efectos persuasivos empleados para representar las manifestaciones y sus representantes.

\section{Lenguaje oral}

En lo que compete al lenguaje oral, se enfatizó en la determinación de lo que puede resultar explícitamente comunicativo (en el sentido de mensaje 
consciente y deliberado) o simplemente informativo. Para ello, se retomaron algunos de los componentes de la propuesta clásica de Trager (1961) y se efectuaron algunas adaptaciones en función de las características que presenta el material de análisis:

(a) Origen de voz (personaje: manifestante, autoridad, periodista, etc...)

(b) Paralenguaje

-Calificadores vocales: intensidad (débil-fuerte), altura tonal (alta-baja).

-Segregados vocales: sonidos de acompañamiento, asentimiento y pausas.

\section{Lenguaje de la imagen-movimiento con sonido}

Dado el interés por las relaciones intersemióticas entre imagen y discurso oral, se toma la propuesta de Vergara (2010), quien utiliza el constructo imagen-movimiento con sonido, que permite abarcar la temporalidad que tradicionalmente excluye la idea de producto audiovisual. Dicho constructo toma en consideración aspectos como los planos, las secuencias, la perspectiva, el movimiento de cámara, la duración y la frecuencia.

En la tabla que aparece a continuación, se muestran los distintos componentes empleados en el sistema de transcripción de las noticias seleccionadas:

Tabla 2. Sistema de transformación

Componentes multimodales

\begin{tabular}{ll}
\hline Tiempo & Duración en segundos. \\
\hline Imagen & Descripción de imágenes que van apareciendo en pantalla. \\
\hline Texto escrito & $\begin{array}{l}\text { Información escrita que el medio presenta: encabezados, } \\
\text { nombres, títulos, logos. }\end{array}$ \\
\hline Discurso oral & $\begin{array}{l}\text { Discurso oral de los distintos participantes: periodistas, } \\
\text { entrevistados (autoridades, manifestantes, terceras personas). }\end{array}$ \\
\hline Efectos de & $\begin{array}{l}\text { Planos de cámara: primero, completo, medio, americano. } \\
\text { grabación }\end{array}$ \\
$\begin{array}{l}\text { Efectos de cámara: acercamiento, alejamiento, picada, travelling, } \\
\text { insert. }\end{array}$ \\
\hline $\begin{array}{l}\text { Relación } \\
\text { texto-imagen }\end{array}$ & $\begin{array}{l}\text { Se retoman categorías desarrolladas por Len Unsworth (2006): } \\
\text { complementariedad, aumentación, presentación, instanciación. }\end{array}$ \\
\hline
\end{tabular}

Fuete: elaboración propia

\section{Resultados}

Las noticias que se examinan aquí muestran una serie de características compositivas homólogas, las cuales conviene incluir con miras a analizar la representación de las protestas concernientes a las reivindicaciones del 
sector educación durante la huelga desarrollada en el primer semestre del año 2014.

Para la determinación de las características compositivas y los recursos semióticos, se identificaron dos elementos fundamentales, en cuyo emplazamiento (framing) es posible vislumbrar una combinación de distintos recursos. Dichos elementos corresponden a los actores o participantes que conforman la noticia y la narrativa en la que están inscritos.

\section{El cuadro de la manifestación}

Se reconocen cuatro tipos de participantes y los manifestantes que protestan por la ausencia de pago (para efectos del presente análisis se dividen entre las personas entrevistadas y la multitud que asiste a las concentraciones). A su vez, están las autoridades gubernamentales encargadas de llevar a cabo la gestión de pago y terceras personas que, según el medio, fueron afectadas por las manifestaciones. Como un cuarto participante de carácter omnisciente, están los periodistas quienes representan la posición del medio televisivo en cuestión.

Los manifestantes, como se indicó, aparecen representados de dos formas distintas: en primer lugar, a través de las entrevistas en las que estos externan sus criterios en torno a la disconformidad por el pago; y en segundo lugar, por medio de la multitud de personas que se hacen presentes en las distintas marchas. Este aspecto es básico pues interesa dirimir la manera en que son representados los actores que forman parte de una disputa política. Como señala Rancière (1996), existe una oposición entre la mera articulación fónica (phoné) emparentada con el "gemido" y la articulación discursiva (logos), que supone el reconocimiento de las distintas partes implicadas en la contienda política.

\section{Imagen 1: Entrevista a manifestantes en video 1}

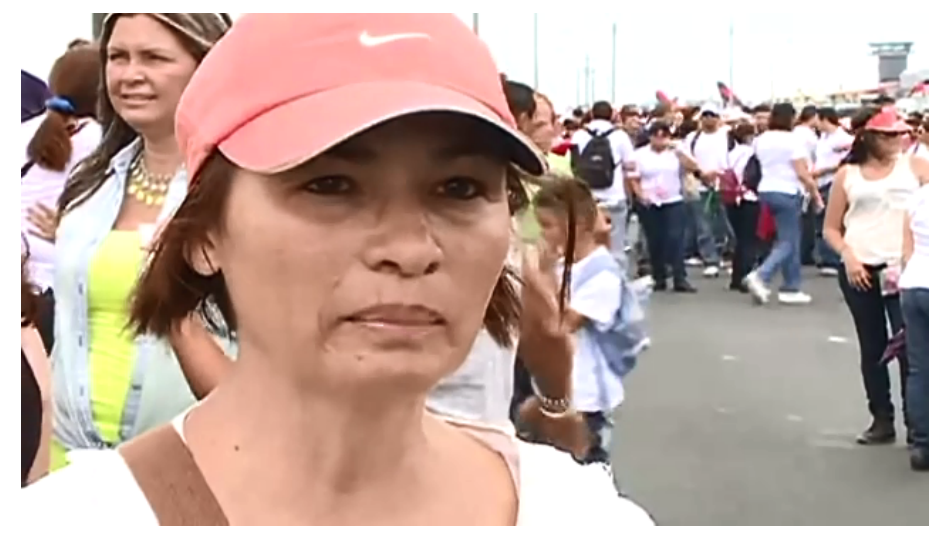

Fuente: Noticias REPRETEL, 2014a. 
Imagen 2: Entrevista a manifestantes en video 3

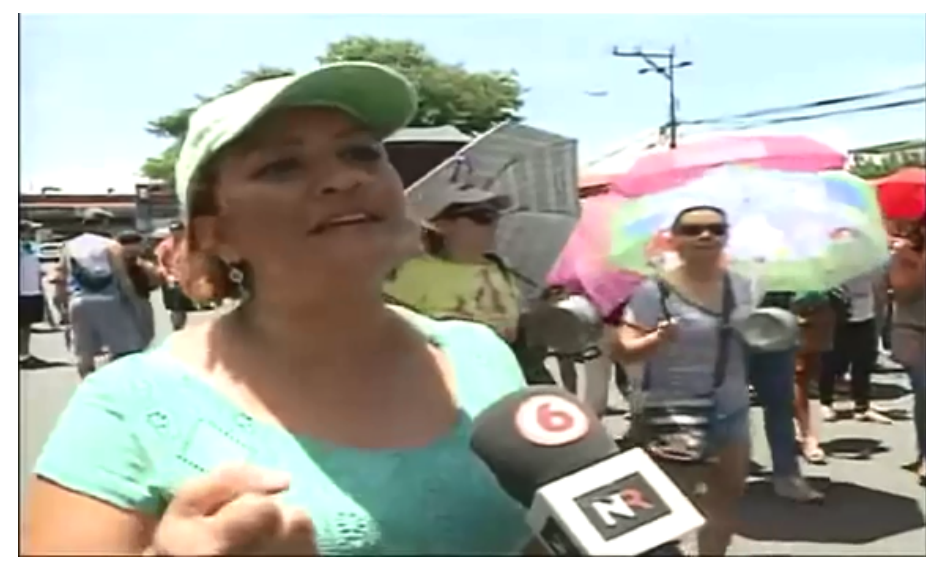

Fuente: Noticias REPRETEL, 2014c.

En las imágenes que se presentan arriba, se muestra la ubicación dentro de la toma de dos manifestantes al momento de ser entrevistadas. Si se divide el cuadro de la toma en subcuadrantes, dicha disposición correspondería, aproximadamente, a la marca en gris que se muestra en la figura que aparece a continuación:

Figura 2: Cuadrante de ubicación de personas entrevistas

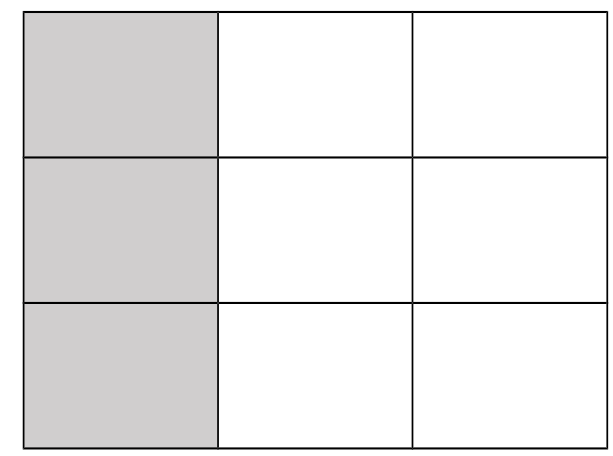

Fuente: elaboración propia.

El espacio en blanco genera así un efecto de profundidad de campo, en el cual se configuran dos espacios disímiles de enunciación de la protesta: uno correspondiente a una colectividad de la cual es posible plantear generalizaciones; y otro que presenta casos concretos y específicos, es decir, un espacio en el que se remarca una instancia subjetiva y, por lo tanto, potencialmente emotiva. Entonces, se podría argüir que esa zona de profundidad es el "blanco" mismo de la toma, es decir, el objetivo composicional que devela la captura en movimiento. 
En esta misma línea, son frecuentes las panorámicas descriptivas a través de las rotaciones de cámara, en la cuales se acentúa la magnitud del movimiento, al mostrar la gran afluencia de manifestantes que se adhiere al movimiento. Dicho aspecto no reviste un cariz favorable o desfavorable en sí mismo; no obstante, su conjunción con otros elementos del marco de noticia conlleva sutiles efectos persuasivos que se decantan por la segunda opción. A tal propósito, véase la siguiente imagen correspondiente a la misma noticia reseñada anteriormente:

Imagen 3: Oficial de policía y manifestantes en video 1

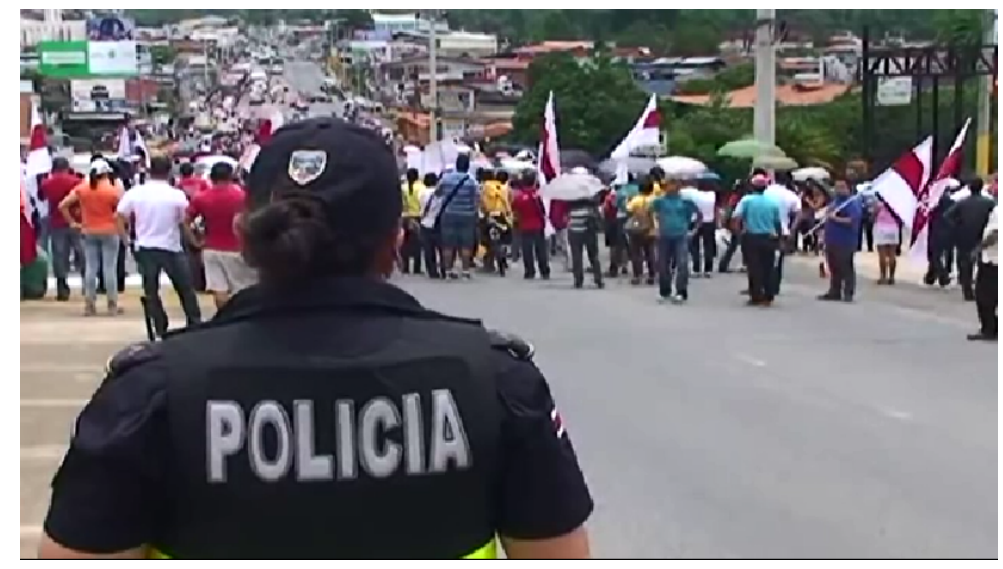

Fuente: Noticias REFPRETEL, 2014a.

En este caso, se trata de una toma construida, que muestra la imagen de una oficial de policía que se encuentra de espaldas (en cuyo uniforme se puede leer con claridad la palabra "POLICÍA"), frente a un grupo de manifestantes que marchan en sentido contrario. La imagen ubica dos escenarios diferentes, el agente inscriptor de la ley y el objeto de su inscripción. Una posible interpretación al respecto consiste en plantear que, a través del encuadre que presupone la toma, el medio busca evocar la alteración del orden público, delineando así los distintos papeles que performan los actores que confluyen en la escena.

Respecto de la figura 4, ocurre lo que Smith, McCarthy, McPhail y Augustyn (2001) denominan un efecto de parcialidad selectiva y parcialidad descriptiva, pues si bien el movimiento social obtiene atención por parte de los medios, el cubrimiento mediático representa la protesta social en formas que neutralizan o socavan el mismo movimiento. De esta forma y siguiendo a estos autores, los medios de comunicación no necesariamente representan la protesta social en forma consistente con los intereses del movimiento; por el contrario, pueden representarla de modo que compliquen sus esfuerzos para comunicar sus mensajes. 
El mismo título de la noticia delimita el carácter de la alteración evocada: "Educadores planean bloquear principales vías este lunes". En la noticia, se alude concretamente a un bloqueo en la zona de Pérez Zeledón; no obstante, se señala, por un lado, el planeamiento de una acción ("bloquear las principales vías") que no está presente en las declaraciones brindadas por los manifestantes y; por otro lado, se generaliza sinécdoque la acción puntual sobre la cual se informa, a lo que se entiende como una acción que comprende todas las vías principales del país.

Así pues, la conjunción de la información que ofrece la información textual respecto a la información que se brinda en el reporte periodístico conlleva un carácter tendencioso, en la medida en que se magnifica el impacto potencial de la protesta.

En el nivel del discurso oral, se presentan enunciados en la narración del periodista que acentúan la tesis anteriormente esgrimida:

Video 1:

Periodista:

00:08- 00:14

este viernes los trabajadores de la educación nuevamente se manifestaron en diversos puntos del país $\uparrow$ | y no en una sola marcha como al inicio $\uparrow \mid$

En este caso, el adverbio "nuevamente" constituye un marcador de tiempo que presenta la manifestación como un accionar reiterativo, el cual acrecienta, además, su intensidad respecto a su conformación inicial.

Video 1:

\section{Periodista:}

00:41- 00:47

los manifestantes insisten en que $\rightarrow$ | pese a sentirse cansados $\downarrow \mid$ no van a abandonar el movimiento $\uparrow \mid$ hasta que le paguen $\rightarrow \mid$ ha:sta el último de los afectados $\downarrow \|$

En concomitancia con el encuadre señalado aquí, la fórmula "pese a sentirse cansados" que aparece en esta segunda intervención, por parte del mismo periodista, tiende a posicionar las demandas de los manifestantes como tozudas y estos como intransigentes. Esto se contrapone con la alusión que indica "hasta que le paguen al último de los afectados", y se enfatiza el carácter de la locución adversativa "pese a", redoblado, además, en razón del alargamiento vocálico que el periodistas realiza en la palabra "hasta". En esta misma línea, las imágenes-movimiento con sonido que se muestran, en ambos casos, corresponden a grupos de manifestantes que marchan en distintas locaciones, con lo cual se genera una relación de complementariedad aumentativa que, en este caso, refuerza la idea de insistencia destacada por el medio.

\section{La reificación de la insistencia}

Como señala Fairclough (1995), un elemento sustantivo mediante el cual los medios presentan las noticias es la configuración de narrativas. Las narrativas, por lo común, distinguen dos facetas principales: una trama, que consiste en una serie cronológica ordenada de eventos y sus respectivos 
participantes; y la presentación, que consiste en la forma en que la trama es desarrollada y organizada en un texto particular.

La secuencia de discurso oral que se presenta a continuación permite visualizar algunos aspectos relevantes de la narrativa que construye el medio sobre las protestas y sus participantes:

Video 2:

Sindicatos se mantienen en huelga

\section{Periodista:}

el llamado a retomar $\uparrow \mid$ las aulas $\uparrow \mid$ por parte del presidente

00:02- 00:14 luis guillermo solís en cadena nacional no funcionó $\downarrow \|$ y la huelga se mantiene $\uparrow \mid$ en su tercera semana $\downarrow \|$ dos pagos se han realizado y la promesa es normalizar la situación el 26 de mayo $\uparrow \mid$ y finalizar con todo lo adeudado el $29 \downarrow \|$

Presidente:

hemos completado $\uparrow \mid$ al menos $\rightarrow \mid$ ocho $\uparrow \mid$ iniciativas para atender la grave situación planteada por el incumplimiento de 00:15- 00:39 pago $\downarrow||$ este demuestra nuestro compromiso $\uparrow \mid$ y la buena fe que nos anima $\downarrow \|$ la familia costarricense heredó un problema $\downarrow$ nos atañe $\uparrow \mid$ entonces $\uparrow \mid$ a todas $y$ todos $\uparrow \mid$ contribuir por igual con su solución $\uparrow \mid y$ con el restablecimiento $\uparrow \mid$ inmediato del curso lectivo $\downarrow \|$

\section{Periodista:}

00:41- 00:50 los educadores rechazan la petición de regresar a clases $\uparrow$ esta tarde lo confirmaron en una conferencia de prensa $\uparrow \|$ aseguran que la huelga se mantiene y que se reprogramarán las clases perdidas y las pruebas que no se realizaron $\downarrow \|$

\section{Presidente ANDE:}

el señor presidente tiene el derecho a salir en su cadena $\uparrow \mid y$ decir $\uparrow \mid$ todo lo que diga $\uparrow \mid$ porque es el señor presidente $\downarrow \|$ nosotros somos un grupo de trabajadores $\uparrow \mid$ que le está diciendo al patrono $\uparrow \mid$ pague $\downarrow \|$ eso es todo $\downarrow \|$ en este 00:51- 01:23 momento $\uparrow$ nosotros $\downarrow$ nos $\downarrow$ eh $\downarrow$ podemos sentar si me llaman a las cinco de la tarde $\uparrow \mid$ me siento a ver $\uparrow \mid$ y buscar posibilidades $\uparrow \|$ así también nos lo dejó claro $\uparrow \mid$ doña sonia marta $\downarrow \|$ que simple y sencillamente las $\rightarrow \mid$ propuestas que nos han dado $\uparrow \|$ no son las que nosotros queremos $\downarrow$ que es el pago justo $\uparrow \mid$ e inmediato $\downarrow \|$

Viceministra de Educación:

nosotros sabemos $\uparrow \mid$ que $\uparrow \mid$ que hay una situación $\uparrow \mid$ de conflicto a nivel salarial $\uparrow \mid$ que estamos arreglando $\uparrow \|$

01:27-01:44 entonces $\uparrow \mid$ nosotros $\uparrow \mid$ sabemos que los $\downarrow \mid$ los $\downarrow$ los docentes $\uparrow \mid$ necesitan su salario $\uparrow \|$ entonces $\uparrow \mid$ lo que estamos | haciendo ver es que $\uparrow \mid$ se les está pagando $\downarrow$ se les va a pagar $\downarrow \|$

Periodista:

mientras en el MEP trabajan en una directriz para 01:45- 01:53 reprogramarlas pruebas lo más pronto posible $\uparrow \mid$ aunque aún no tienen calendarizadas las fechas $\downarrow \| l$ se espera que más sindicatos se unan $\uparrow \mid$ al llamado huelga $\downarrow||$ 
La serie cronológica que presenta esta narración comprende los siguientes eventos: 1) exposición del conflicto: "La huelga se mantiene en su tercera semana"; 2) llamado de restitución del curso lectivo: "Nos atañe entonces a todas y todos contribuir por igual con su solución y con el restablecimiento inmediato del curso lectivo"; 3) rechazo de la propuesta por parte de los educadores: "Los educadores rechazan la petición de regresar a clases (...) aseguran que la huelga se mantiene"; 4) negación del conflicto: "Se les está pagando, se les va a pagar"; 5) augurio de exacerbación del conflicto: "Se espera que más sindicatos se unan al llamado huelga".

La trama en su conjunto configura una reificación de la insistencia que, en consonancia con la prerrogativa que tienen las fuentes en favor de la postura del Gobierno sobre los representantes del movimiento sindical (participantes), constituye la protesta en una porfía en contra del sentido común. De esta forma, el verbo "mantener" que anuncia el título de la noticia, da cuenta de una permanencia que es juzgada como desacertada en función de la ordenación de los eventos narrados y, especialmente, en la forma en que el periodista presenta la trama.

La ilación narrativa se refuerza a través del nexo con la imagen-movimiento con sonido que se presenta durante la narración oral del periodista y con el extracto de la Cadena Nacional en la que habla el presidente, donde se presenta una intercalación en la que, por momentos, la relación imagendiscurso oral es de complementariedad o de instanciación (1. Imagen del presidente hablando, 2. Imagen de manifestantes en las calles). Esto privilegia ya sea el sonido de la narración periodística o la voz del mandatario sobre el sonido ambiente de los manifestantes que cuenta con un gradiente de volumen menor.

$\mathrm{Si}$, siguiendo a Velásquez (2004), se tiene en cuenta que el marco de la noticia corresponde a ese esquema bajo el cual se escribe o dice la noticia, es decir, ese esquema que tiene unas características sobresalientes que producen unos mensajes explícitos o implícitos para que el público interprete, evalúe $y$, eventualmente, piense en el tratamiento que se debe dar al asunto problemático sobre el que da cuenta la noticia, que en este caso se refiere a las protestas concernientes al sector educación, resulta imperativo comprender el lugar que ocupa la narrativa de la insistencia en el encuadre general con cual se construyen las noticias analizadas.

El carácter avieso de la insistencia es tematizado mediante las consecuencias que el medio enfatiza que generan las protestas. Una forma de introducir dichos efectos es por terceras personas, quienes son presentadas como "neutrales" al acontecimiento informativo, es decir, no están manifestándose ni forman parte de las autoridades de Gobierno a cargo de la situación.

En el siguiente extracto, se presenta la opinión de una mujer que se encontraba en un atascamiento vial producto de un bloqueo realizado en la zona caribe del país: 
Video 4:

01:21- 01:35

\section{Entrevistada:}

tenemos como una hora y media más o menos de estar acá en la presa $\downarrow$ mucho calor $\uparrow \mid$ andamos con una bebé verdad $\uparrow \mid$ entonces es bastante complicado $\downarrow$ sin embargo $\uparrow \mid$ diay ellos tienen todo el derecho $\downarrow \mid$ también verdad y yo creo que el gobierno pues debería de $\downarrow$ de tomar en cuenta esta situación $\uparrow \mid$

Este proceder constituye, al igual que la configuración de la estructura narrativa anteriormente señalada, un mecanismo persuasivo, que busca que las proposiciones dadas por el medio parezcan verdaderas o plausibles (Van Dijk 1990). En este caso, se presentan varias estrategias persuasivas, en primer lugar, se subraya la naturaleza factual de los acontecimientos, en tanto se describen y amparan mediante evidencia brindada por una persona que cumple la función de "testigo".

Si, como señala Rovira-Sancho (2013), los medios masivos crean liderazgos a través de estrategias de personificación que dotan de "rostro" a las protestas; en este caso, el énfasis en los rostros "damnificados" constituye una estrategia que dota a las protestas del sector de educación de un rostro tácito pero insidioso, el rostro siempre indeseado de los "daños colaterales".

Aunado a esto, se presenta una estructura relacional sólida de los hechos que, en este caso particular, enfatiza la relación causa-consecuencia entre distintos acontecimientos mediante un recurso multimodal. De esta manera, durante la entrevista que se le hace a la mujer en el embotellamiento, la imagen-movimiento con sonido presenta una relación de complementariedad (imagen y audio de la mujer hablando) y una relación instanciación, mediante la irrupción de una escena en la que se muestra un ángulo que amplía la presa, correspondiente a la siguiente imagen:

Imagen 4: Embotellamiento Ruta 32 en video 4

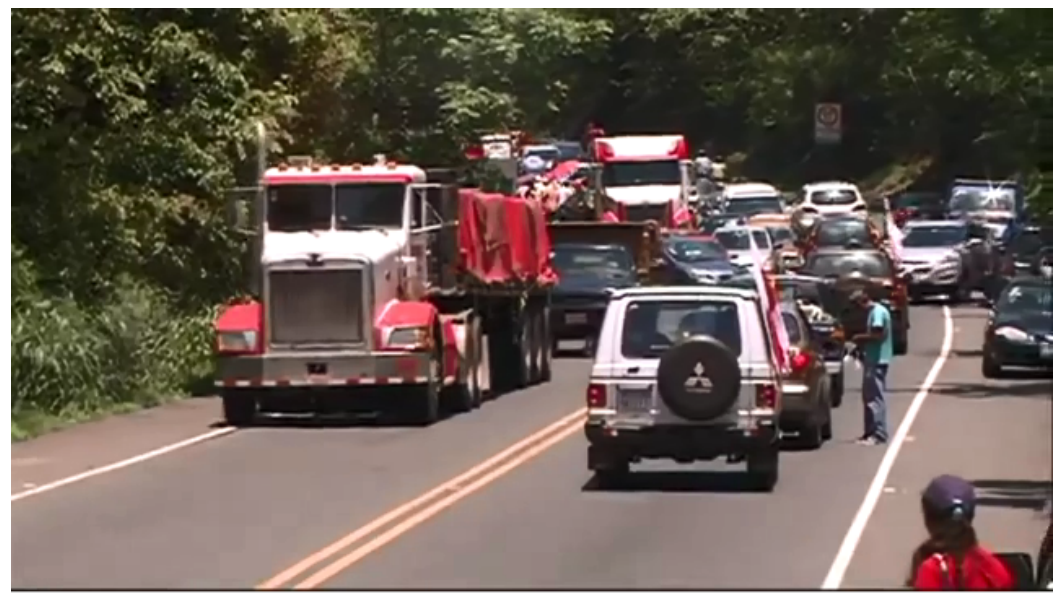

Fuente: REPRETEL, Noticias, 2014d. 
La estrategia empleada busca, como se indicó anteriormente, hacer plausible el reporte noticioso; dicho proceder encuentra, por su parte, otro asidero mediante la proporción de información que apela a un contenido emocional concreto. A pesar de la opinión favorable que muestra la mujer al final, la forma en que su testimonio se presenta hace énfasis en las consecuencias que apelan al sentir humano; a saber: el trascurrir hora y media con calor dentro de un carro ocupado por un bebé, es incluso potencialmente peligroso para la integridad del menor.

La selección de esta entrevista no es en absoluto anodina; por el contrario, transmite una visión ideológica particular, siendo que se invoca sutilmente la contraposición de los intereses del sector gremial y los del resto de población, y se apela al componente emotivo en el que se representa dicha generalidad en función de un caso particular. Estos elementos muestran, en su conjunto, que la reificación de la insistencia a la cual se alude en este apartado adquiere un cariz de desavenencia que es representado a través distintas estrategias narrativas y de recursos multimodales.

Como síntesis de este apartado, conviene recordar, junto a Kress y van Leeuwen (2001), que vivimos en una sociedad multimodal que crea significado a través del despliegue conjunto de una combinación de recursos semióticos, a saber: gestos, sonidos e imágenes visuales. Este aspecto es gran importancia para reflexiones que se han abordado en el presente artículo, pues es precisamente la conjunción de distintos recursos semióticos lo que permite afirmar que el abordaje noticioso de las protestas sociales se decanta, en el caso específico recién analizado, por una desvalorización de los artífices de la huelga y de las razones que crean sus protestas.

Una descripción periodística de determinados hechos o de las características de fenómenos específicos, así como de la recopilación de testimonios de distintos actores, adquiere un aspecto distinto cuando son aparejados con otros recursos multimodales. Un caso destacado, como hemos podido ver mediante en ejemplos, lo constituye las imágenes. La imagen, como señala Aumont (2007), es en rigor asignable a uno u otro actante social, lo que nos da pie para argüir que la semiosis social a la que apunta la representación de las protestas sociales, por parte del medio comunicativo seleccionado, hace de ese actante uno contrario a lo que Norman Fairclough (2001) llama el "sentido común", que no es otra cosa que el producto de la ideología de los grupos dominantes, que se arrojan el derecho de definir el sentido de lo común.

\section{Reflexiones finales}

En lugar de conclusiones, hemos optado por hablar de reflexiones finales, pues el abordaje desarrollado en el presente texto constituye una aproximación incipiente. Con esta procuramos acercarnos a la representación mediática de un fenómeno de tanto impacto como son las protestas sociales, desde un punto de vista multimodal. En este sentido, 
nuestras reflexiones apuntan; por un lado, a subrayar algunos aspectos esenciales de nuestra aproximación y; por otro, a visibilizar algunas vías posibles de análisis ulterior.

Quizá el aspecto neurálgico al que apunta el presente artículo consiste en remarcar los efectos de manipulación que inducen ciertos tratamientos periodísticos. Como señala Van Dijk (2009), manipular discursivamente la manera en que los receptores comprenden un evento, acción o discurso, en ocasiones, es muy importante, pues entre otras cosas, puede afectar "a las normas y valores usados para evaluar los sucesos y las personas y condenar o legitimar acciones" ( 368).

En el caso que nos ocupa, la combinación de recursos multimodales, con los cuales se presentan las protestas de los educadores, induce sistemáticamente a volcar al televidente en contra de los artífices de la protesta y representar sus causas como ajenas a la mayoría de la población. Este accionar a todas luces contradice el carácter supuestamente imparcial de los medios de comunicación. Entonces, parece imperativo tomar la palabra de Foucault (2001), quien señala:

En una sociedad como la nuestra, la verdadera tarea política es criticar el juego de las instituciones aparentemente neutras e indepen dientes; de criticarlas y atacarlas de tal manera que la violencia política que se ejerce oscuramente en ellas sea desenmascarada y que pudiésemos luchar contra ellas (1364).

Partiendo del hecho de que los medios comunicación tienen un evidente impacto en la construcción, reproducción y mantenimiento de opiniones, actitudes, emociones y reacciones de sus perceptores (Rodrigo 1995), resulta fundamental tener en cuenta la forma en que determinados fenómenos sociales son enmarcados por parte de los medios de comunicación.

El análisis de las noticias que se presenta en este artículo da cuenta de una serie de mecanismos persuasivos, los cuales son implementados a través de distintos recursos multimodales; para ello, es básico tener presente la noción de cuadro de noticia.

El hecho de tratar de discernir la disposición de cada uno de los elementos que entran en dicho cuadro constituye una tarea compleja en la que intervienen múltiples factores y, para la cual, el análisis multimodal no tiene una respuesta preestablecida. La interrelación texto-contexto hace necesario un análisis particularizado de cada producto comunicativo, pues el significado que pueda tener un enunciado, un enfoque de cámara o la misma disposición del tiempo varía de acuerdo al contexto. 
Tanto el encuadramiento que se hace de los manifestantes como la "narrativa de la insistencia" que se analizan en este artículo deben leerse como parte de un contexto social específico del cual forma parte la empresa de comunicación en cuestión. Se ha demostrado, a través de estudios cuantitativos y cualitativos del proceso de producción de la comunicación, que los medios seleccionan, filtran, discriminan y publican la información de acuerdo con ciertos estándares que responden a políticas e intereses internos de cada medio. Al ser los medios de comunicación también empresas (McCarthy, McPhail y Smith, 1996), tienen un sesgo ideológico que repercute directamente en su práctica, la cual convierten en una práctica política que, inexorablemente, permea la imagen en relación con los procesos de protesta social y sus participantes.

Dado que este artículo se centra en los productos informativos que difunde un medio de comunicación en particular y no en la recepción que tienen dichos productos, no es posible discernir sus efectos por parte de la población. De forma general, para ulteriores procesos de investigación, se considera esencial acompañar este tipo de abordaje con estudios de recepción que permitan dilucidar las distintas posibilidades de incorporación de un mensaje; y de manera específica, en lo que compete al análisis de la representación de las protestas sociales por parte de los medios comunicación, pues constituyen un vórtice neurálgico de las trasformaciones sociales que acaecen en toda sociedad.

\section{Bibliografía}

Aumont, Jacques. 2007. La imagen. Barcelona: Paidós.

Bourdieu, Pierre. 2001. Sobre la televisión (1ed.). Colección Argumentos. Barcelona: Anagrama.

Calsamiglia, Helena. y Amparo Tusón. 2007. Las cosas del decir. Manual de análisis del discurso. Barcelona: Editorial Ariel.

Díaz, Rainer, Andrea Bührmann, Encarnación Gutiérrez, Werner Schneider, Gavin Kendall y Francisco Tirado. Mayo 2007. «El Campo de análisis del discurso Foucaultiano. Características, desarrollos y perspectivas». Forum Qualitative Social Research, 8(2): 1-28.

Fairclough, Norman. 1995. Media discourse ( $1^{\circ}$ ed.), London: Hodder Arnold. 
Fairclough, Norman. 2001) Language and Power ( $2^{\circ}$ ed.). United Kingdon: Pearson Education Limited.

Foucault, Michel. 2001. De la nature humaine: justice contre pouvoir. Dits et Écrits I. 1954-1975. Paris: Quarto Gallimard.

Halliday, Michael. 1978 El lenguaje como semiótica social. México: FCE.

Jewitt, Carey. 2009. An Introduction to Multimodality. En Jewitt, C. (Ed.). The Routledge Handbook of Multimodal Analysis. London and New York: Routledge.

Kress, Gunther. y Theo Van Leeuwen. 2001. Multimodal Discourse: The Modes and Media of Contemporary Communication. London: Arnold.

Martín, Salvio. 2012. Multimodalidad y estrategias discursivas: un abordaje metodológico. Revista Latinoamericana de Estudios del Discurso, 12(1): 57-75.

McCarthy, John; Clark McPhail y Jackie Smith. Junio 1996. «Images of Protest: Dimensions of Selection Bias in Media Coverage of Washington Demonstrations», 1982 and 1991. American Sociological Review, 61(3): 478-479.

Mena, Fabio. Marzo 2014. «Planilla del MEP alcanza 75 mil empleados y continúa con nombramiento de docentes». CR Hoy. Recuperado 20 de abril, 2014, de http://www.crhoy.com/planilla-del-mep-alcanza-75-milempleados-y-continua-con-nombramiento-de-docentes-8244|7|9n2x/

Mora, Sindy. 2009-2010. «Desunión y distanciamiento: Conflictos e interpretaciones de la huelga del Magisterio Nacional de 1995». Anuario de Estudios Centroamericanos, 35-36: 149-170.

O’Halloran, Kay. 2012. «Análisis del discurso multimodal». Revista Latinoamericana de Estudios del Discurso, 12(1): 75-97.

Rancière, Jacques. 1996. El desacuerdo. Política y filosofía ( $1^{\circ}$ ed.), Buenos Aires: Ediciones Nueva Visión. 
REPRETEL. Mayo 2014a. «Educadores planean bloquear principales vías este lunes». Costa Rica: REPRETEL. Recuperado 9 junio 9, 2014 de https://www.youtube.com/watch?v=CaQaWqyOkBI

REPRETEL. Mayo 2014b. «Huelga se mantiene y otros sectores se unirán a las manifestaciones». Costa Rica: REPRETEL. Recuperado 9 junio, 2014, de https://www.youtube.com/watch?v=9oyUPKCZfiE

REPRETEL. Mayo 2014c. «Manifestantes realizaron marchas en Heredia y Cartago». Costa Rica: REPRETEL. Recuperado 9 junio, 2014, de https://www.youtube.com/watch?v=elxXJncuXc4

REPRETEL. Mayo 2014d. «Servicios de salud y muelles podrían sumarse pronto a la huelga. Noticias». Costa Rica: REPRETEL. Recuperado 9 junio, 2014, de https://www.youtube.com/watch?v=502iu-A2xJE

Rodrigo, Miquel. 1995. Los modelos de la comunicación ( $2^{\circ}$ ed.). Madrid: Tecnos.

Romanutti, María. 2012, setiembre/noviembre. «Identidad y protesta social. Contribuciones al estudio de su relación». Andamios, Revista de Investigación Social, 9(20): 259-274.

Rovira, Guiomar. 2013, enero/abril. «Activismo mediático y criminalización de la protesta: medios y movimientos sociales en México». Convergencia, Revista de Ciencias Sociales, (61): 35-60.

Saborío, Aixa y Roxana Zúñiga. 2006. Los noticiarios son noticia. (Tesis no publicada en Ciencias de la Comunicación Colectiva con énfasis en Periodismo). Universidad de Costa Rica, San José, Costa Rica.

Smith, Jackie, John McCarthy, Clark McPhail y Boguslaw Augustyn. 2001, june. «From protest to agenda building: description bias in Media Coverage of Protest events in Washington, DC. Social Forces.» The University of Carolina Press, 79(4): 1397-1423.

Trager, George. 1961, january. «The Typology of Paralanguage». Anthropological Linguistics, 3(1). 
Van Dijk, Teun. 2009. Discurso y poder (1ed.). Barcelona: Editorial Gedisa.

Van Dijk, Teun. (1990). La noticia como discurso. Comprensión, estructura y producción de la información ( $1^{\circ}$ ed.). España: Paidos.

Velásquez, Carlos. 2004. «Cubrimiento televisivo-noticioso de protestas sociales en Colombia.» Palabra Clave, 10: 9-37.

Vergara, Adrián. 2010) El discurso alarmistas en la televisión en Costa Rica: El Discurso sobre la criminalidad en los textos informativos. Dissertation zur Erlangung der Doktorwürde durch den Promotionsausschuss, Universität Bremen, Bremen, Alemania.

Verón, Eliseo. 1993. La semiosis social (1ed.). Barcelona: Gedisa Editorial. 